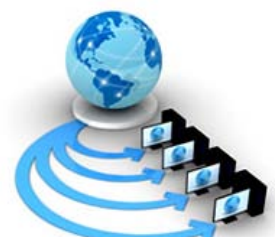

Volume 9, No. 2, March-April 2018

International Journal of Advanced Research in Computer Science

RESEARCH PAPER

Available Online at www.ijarcs.info

\title{
AUTOMATED ASSISTANCE FOR FOUNDATION ENGINEERS(AAFE)
}

\author{
Dharma Reddy Tetali \\ Department of Computer Science and Engineering \\ MLR Institute of Technology \\ Dundigal, Hyderabad, Telangana, India
}

\author{
Pushpa Rani K \\ Department of Computer Science and Engineering \\ MLR Institute of Technology \\ Dundigal, Hyderabad, Telangana, India
}

\begin{abstract}
Foundation is an important part of a building, as it safely transmits the entire building weight down to the earth. If the foundation fails, then the entire structure is likely to collapse. the type of foundation to be adopted for a building varies from soil to soil. There are a wide variety of soils ranging from soft black cotton soils to hard rock soils. It is a difficult task for structural engineers to determine the soil type, and thereby to decide the foundation that is suitable to that soil type. Automated Assistance For Foundation Engineers(AAFE) is a tool developed to assist the structural engineers to determine the soil type based on soil properties and soil test results, and thereby to further decide about the suitable foundation. This paper aims at elaborating the tool, its development and working scenarios.
\end{abstract}

Keywords: AAFE (Automated Assistance For Foundation Engineers),UKSO(United Kingdom Soil Observatory), Capillary Rise Test, Python, PyQt

\section{INTRODUCTION}

There are different types of soils spreading throughout the world. United Kingdom has 700 different types of Soils[1], spreading throughout the country, as shown in the following figure[2].

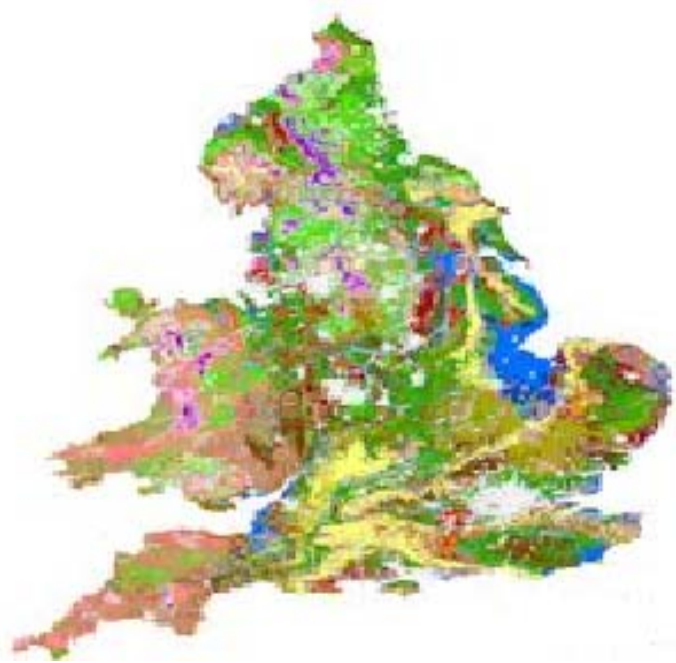

Fig1: Distribution of different types soils in United Kingdom

There are over 19,000 soil series identified in United States of America. Determining the soil type is not an easy task. One has to carefully observe various soil properties like, its color, texture, particle size, wet soil properties and dry soil properties, for determining the type of soil. Also, test like Capillary rise test and soil moisture test helps us to determine the soil type.

AAFE is an user friendly interactive tool, that can be used by foundation engineers to easily arrive at a decision on the type of the given soil. The tool gathers information, by asking various relevant queries on the properties of the soil. The tool also accepts the soil test results as input. The tool determines the type of soil, based on these soil properties and test results. The Capillary rise test is useful in knowing the soil type based on capillary rise. The capillary rise will be relatively more in fine clay type soils and less coarse sandy type soils[4].Lu and Likos developed an analytical solution for analysing the rate of capillary rise in soils[5].

It is a difficult task for the structural engineers to determine the suitable foundation, even after knowing the soil type. This is because, there are many different types of soils existing in different parts of the world, and it is very difficult for the structural engineers to remember all those soil types, along with the foundation type matching to those soil types. AAFE tool assist the structural engineers in determining the suitable type of foundation as well.

\section{I MPLEMENTATION OF AAFE TOOL}

The tool is implemented by using Python[6] and its user friendly layout kit PyQt[7]. PyQt is a Python plu-in binding of the cross-platform Graphical User Interface toolkit.

Following figure shows the entry screen of the AAFE Tool.

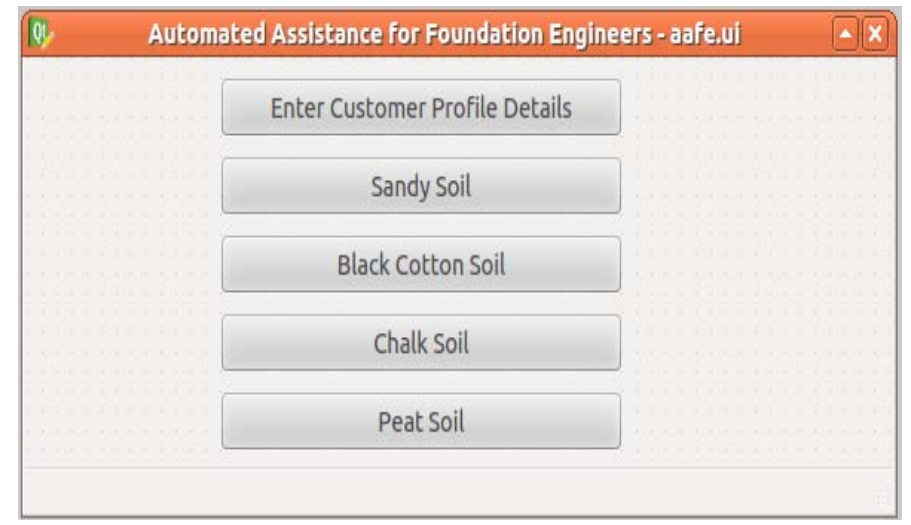

Fig.2:Entry Screen of AAFE Tool

The customer can register himself, by clicking on the push button entitled 'Enter Customer profile Details'. The second button leads to the graphical User Interface screens dealing with Sandy soils, third button deals with Black cotton soils, fourth button deals with Chalk soils and the fifth button deals with Peat soils. 
Following python code snippet shows the corresponding Python function calls to deal with the customer details and different types of soils.

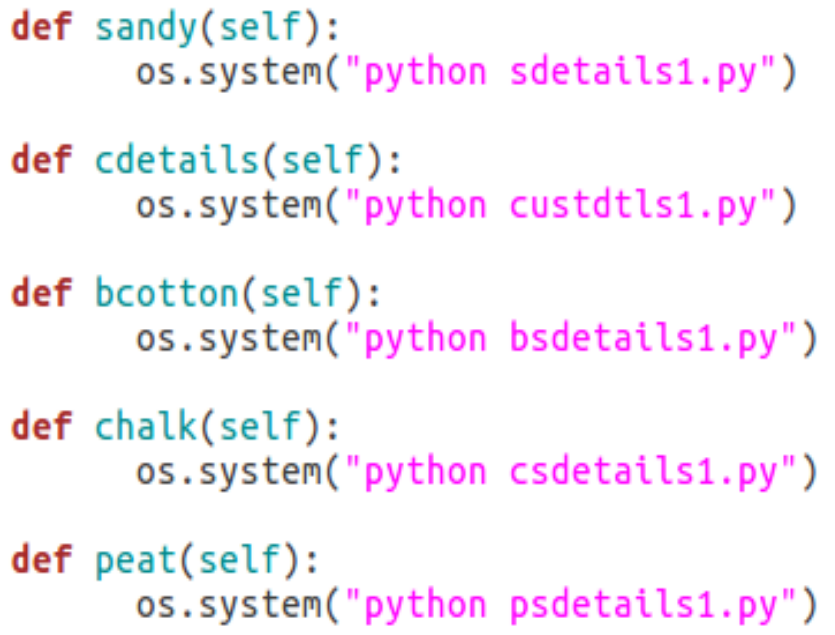

Following is the screen that is useful to store the soil type details into the database.

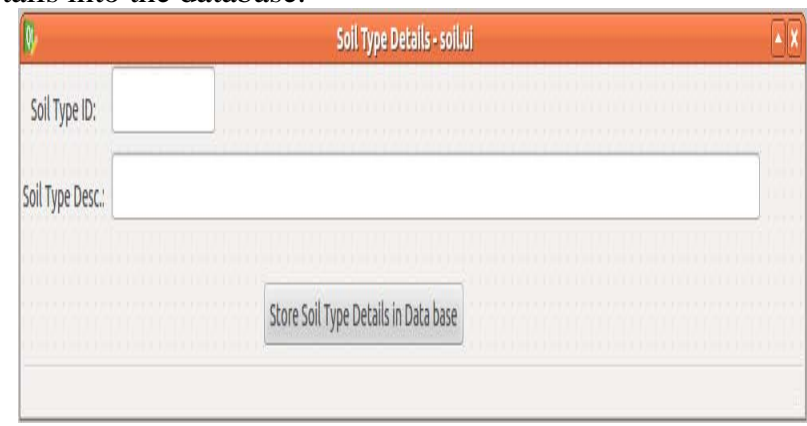

Fig.3:GUI for storing soil type details in Data base

Following screen is useful to deal with Black cotton soils. The particle size of black cotton soils is generally larger than $0.5 \mathrm{~mm}$, and is barely distinguished by naked eye. Its color will be dark grey/black, and such soils develop cracks in Summer.

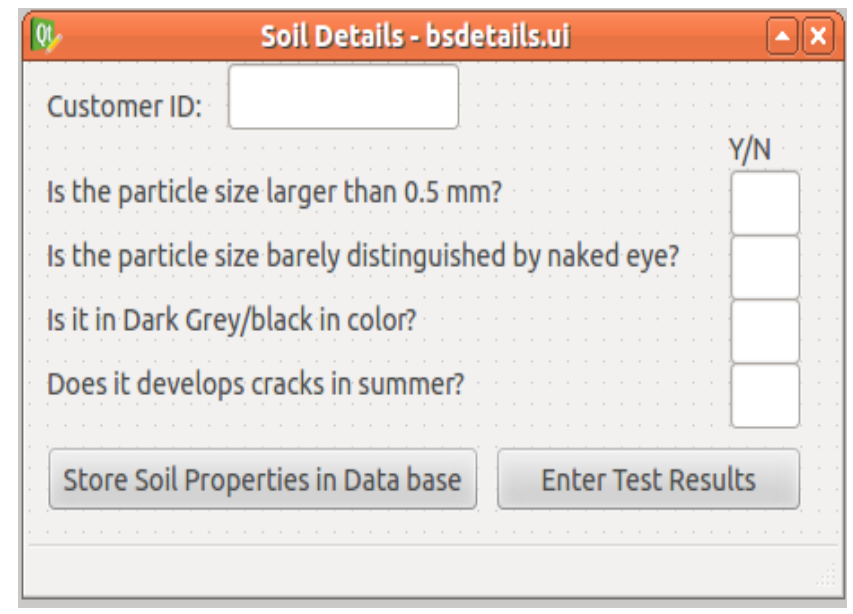

Fig.4:Screen to deal with Black cotton soil properties

Following Python function is used to store the soil properties into the corresponding data base entity.

\section{def insertvalues(self):}

\section{with con:}

$$
\begin{aligned}
& \text { cur }=\operatorname{con} . \operatorname{cursor}() \\
& \text { cid }=\operatorname{str}(\text { self.ui.lineEdit_3.text()) } \\
& \text { s5 }=\operatorname{str}(\text { self.ui.lineEdit_4.text()) } \\
& \text { s6 }=\operatorname{str}(\text { self.ui.lineEdit_5.text()) } \\
& \text { s7 = str(self.ui.lineEdit_6.text()) } \\
& \text { s8 }=\operatorname{str}(\text { self.ui.lineEdit_7.text()) } \\
& \text { cur.execute('INSERT INT0 soilprops } \\
& \text { (cid,s5,s6,s7,s8) } \\
& \text { VALUES(\%s,\%s,\%s,\%s,\%s)',(cid,s5,s6,s7,s8)) } \\
& \text { con.commit() }
\end{aligned}
$$

Soil tests like Capillary rise test and soil moisture test can be conducted on soil samples, and the corresponding soil test results can be stored in the database, by using the following screen.

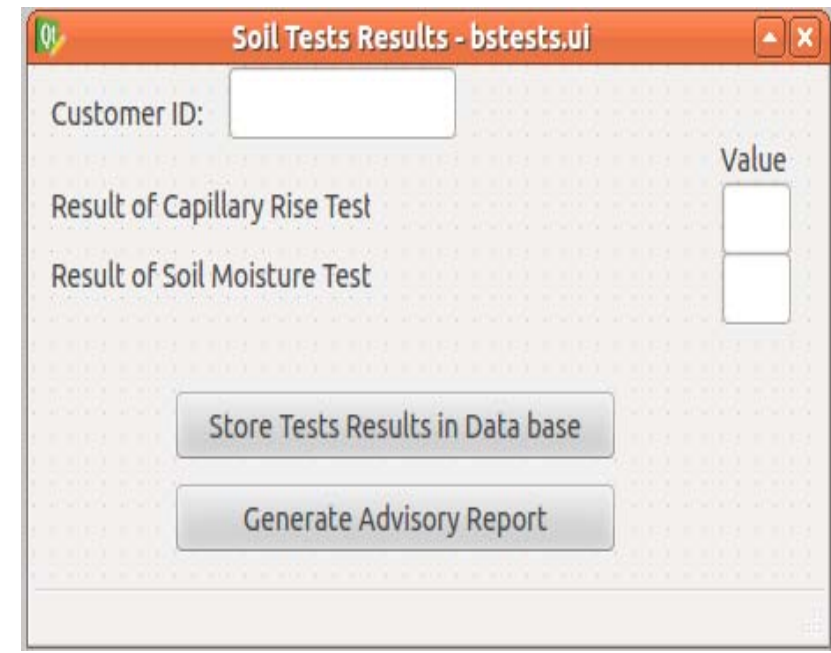

Fig.5: Screen to deal with soil test results

The above screen is also useful to generate the Advisory report containing properties and test results of the given soil sample, the type of the soil ascertained by the system, and the type of foundation, suitable for that soil.

Following code snippet is used to store the test results into the corresponding database entity. 
def insertvalues(self):

with con:

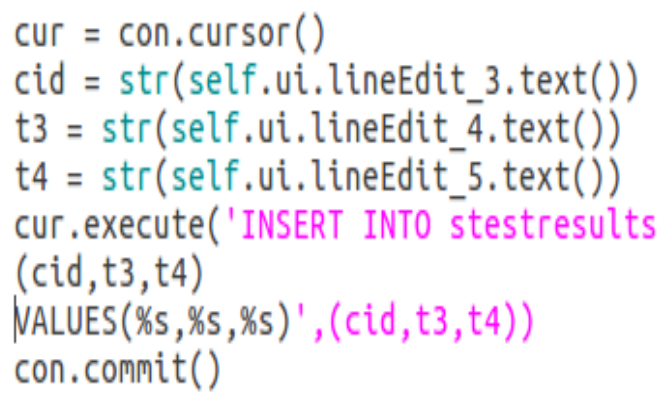

The particle size of the chalk soils in general will be in between $0.2 \mathrm{~mm}$ to $0.5 \mathrm{~mm}$, and the particle is barely distinguished by naked eye. Also, the Chalk soils are generally loose and contain pieces of chalk.

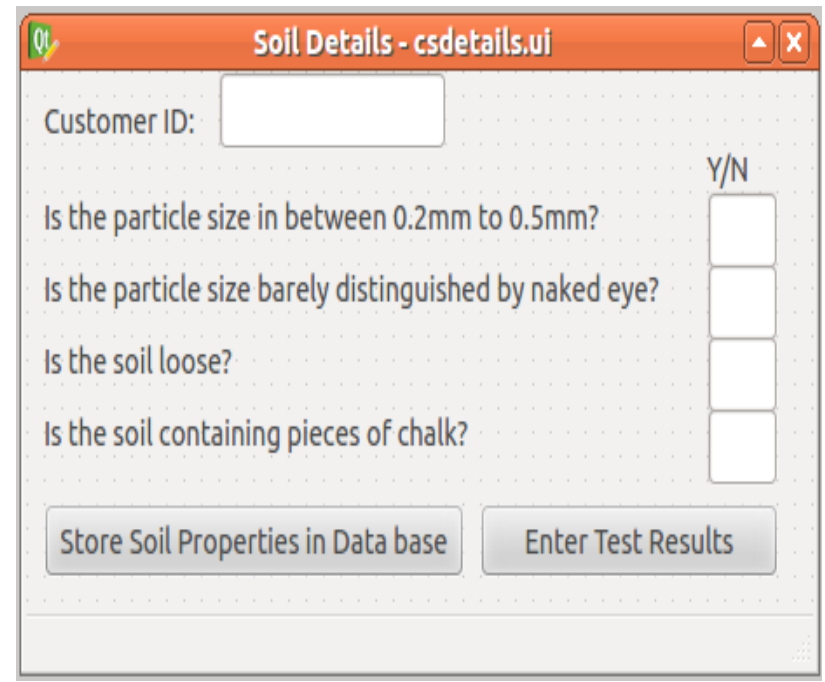

Fig.6: Screen to deal with Chalk soil properties

Following is the graphical user interface for entering the customer details, and thereby to register the customer in the tool. The customer need to give his ID, name, address, Aadhar and Mobile numbers towards the registration.



Fig.7:Customer registration screen def insertvalues(self):

with con:

$$
\begin{aligned}
& \text { cur }=\text { con.cursor }() \\
& \text { aadhar }=\operatorname{str}(\text { self.ui.lineEdit.text()) } \\
& \text { cid }=\operatorname{str}(\text { self.ui.lineEdit_3.text }()) \\
& \text { cname }=\operatorname{str}(\text { self.ui.lineEdit_4.text }()) \\
& \operatorname{addr1}=\operatorname{str}(\text { self.ui.lineEdit_5.text }() \text { ) } \\
& \text { addr2 }=\operatorname{str}(\text { self.ui.lineEdit_6.text }()) \\
& \text { mobile }=\operatorname{str}(\text { self.ui.lineEdit_z.text }()) \\
& \text { cur.execute(' INSERT INTO customer } \\
& \text { VALUES(\%s, \%s, \%s, \%s, \%s,\%s)', } \\
& \text { ((cid, cname, addr } 1 \text {, addr } 2 \text {, aadhar , mobile)) } \\
& \text { con.commit() }
\end{aligned}
$$

Above code is used store the customer details into the corresponding data base entity.

Following is the screen used to store the soil properties and test results of peat soils. The particle size of peat soils, is generally less than $0.5 \mathrm{~mm}$, and those small particles can't be distinguished by naked eye. The soil will be loose, and black in color.

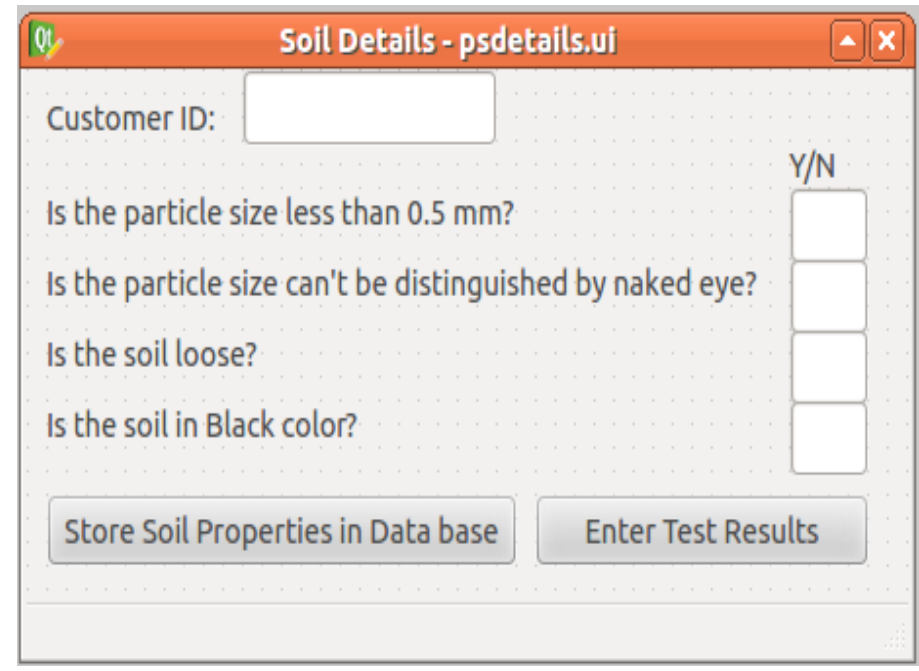

Fig.8: Screen to deal with peat soil properties

Following screen is used to deal with the sandy soils. The particle size of sandy soils is generally greater than $1 \mathrm{~mm}$, and the sand particles are obvious to the naked eye. The soil will be loose, and the water table will be at low level. 
Dharma Reddy Tetali et al, International Journal of Advanced Research in Computer Science, 9 (2), March-April 2018, 115 -118

Customer ID:
Is the particle size obvious to the naked eye?
Is the particle size larger than $1 \mathrm{~mm}$ ?
Is the Soil Loose?
Is the Water table at Low level?
Store Soil Properties in Data base Enter Test Results

Fig.9: Screen to deal with Sandy soil properties

\section{CONCLUSION}

As of now, the system is deciding the soil type based on a list of limited soil properties and test results. In future this list can be further expanded by considering the other soil properties and test results as well.

\section{REFERENCES}

[1] http://www.soil-net.com/primary/ks2/ topic12/topic12_factsheet.pdf

[2] http://www.ukso.org/SoilsOfEngWales/home.html

[3] https://en.wikipedia.org/wiki/Soil_in_the_United_States

[4] http://agrienvarchive.ca/download/measure_cap_rise_soil83 .pdf

[5] https://www.pcprogress.com/Images/Personal/NLu/Publications/NLJ3320 0403.pdf

[6] https://www.python.org/

[7] https://wiki.python.org/moin/PyQt 